\title{
Flight and defense in cats with septal lesions
}

\author{
H. URSIN \\ Department of Physiological Psychology and Institute of Physiology \\ University of Bergen, Bergen 5000, Norway \\ D. C. BLANCHARD and R. BLANCHARD \\ University of Hawaii, Honolulu, Hawaii 96822 \\ and \\ R. URSIN \\ Institute of Physiology, University of Bergen, Bergen 5000, Norway
}

\begin{abstract}
Localized lesions in septal subnuclei or in fornix or stria terminalis did not alter flight or defense behavior in 16 feral cats. Primary changes in fear or defense motivation or in the species-specific defense behavior do not seem to be acceptable explanations for the well established septal influence on avoidance behavior.
\end{abstract}

Lesions and stimulation of specific sites in the septum and amygdala have provided extensive evidence of the joint involvement of these structures in agonistic behaviors of rats and cats. Ursin (1965a, 1965b) has described an area in the cat amygdala from which electrical stimulation elicited flight and in which lesions reduced flight behaviors in feral cats and produced poor active avoidance in tame cats. Andy, Giurintano, Giurintano, and Simpson (1977) report that amygdaloid stimulation reduced the threshold for a "rage" reaction that had been elicited and progressively heightened by increasing levels of electrical stimulation of the perifornical area of the posterior septum. Lesions in the same amygdaloid sites raised the septal-stimulation "rage" threshold; since these amygdaloid sites were related to stria terminalis output, Andy et al. interpreted their findings as indicating amygdaloid modulation via the stria terminalis of an emotional response organized in the septum. The importance of the stria terminalis for defense behavior in cats has been well established (De Molina \& Hunsperger, 1962); however, the possibility exists that the stria terminalis represents an afferent system to the amygdala from the septum for defense behavior (Zbrozyna, 1963). This would also explain the data reported by Andy et al.

The specific components of the "rage" reaction described by Andy et al. (1977) closely resemble the cat defense response observed and measure by Ursin (1964) in a standardized test situation in feral cats, which is elicited by amygdala stimulation (Ursin, 1965b). We have, therefore, investigated the effects of localized septal lesions, including lesions of the stria terminalis and the perifornical septum, on this defense response and on flight in the feral cat, in order to determine the role of septal nuclei for these types of behavior.

\section{METHOD}

Subjects and Housing Conditions

Sixteen adult feral cats, males and females, were used. They were trapped on farms close to the city of Bergen, Norway. The animals could be handled only with heavy gloves and had to be caught in a net for vaccination and anesthetization. The cats were housed individually in wire-mesh cages $(70 \times 70 \times 75 \mathrm{~cm})$ containing one wooden shelf, a sawdust bin, and dishes for milk and boiled fish. The bin and the dishes were changed each morning. At all other times, the cages were closed, and the traffic in the room was kept at a minimum. The animals were handled, even on the early postoperative period. The cats in the neighboring cages were tame in most cases.

\section{Observations}

The responses of the cats to a standardized series of provocations were observed and rated, using a scoring method that has been described in detail elsewhere (Ursin, 1964, 1969). Briefly, the investigator first stood in front of the cage, looking at the cat. Then, the cage door was opened, and a wooden stick was waved in front of the cat. The animal then was touched gently with the stick on the nose and on the back. Finally, the cat was trapped in a net. Occurrence of standard responses was noted during each stage of provocation (see Table 1). The total scores for flight and defense were obtained by summation of the weighted scores within each of the two categories. The testing was done with the experimenter alone with the cats in the animal room.

Preoperatively, six observations were made, two each week for 3 weeks, to the extent that this was possible. Postoperatively, at least four observations were made for each subject. To avoid unnecessary handling of the subjects postoperatively, the behavior was observed with at least 1 week between observations. Usually, the first observation was taken on Postoperative Days 814 , and the subsequent observations were made during the following 4 weeks. In some cases, in particular, when changes were suggested, behavior was followed for several months postoperatively.

The experiments have been performed over several years. All cats were scored by one of us (H.U.); other experimenters have also observed the cats, in order to check interobserver reliability. All scores used in the present investigation were 
Table 1

Scoring Schedule

\begin{tabular}{|c|c|c|c|c|}
\hline \multirow[b]{2}{*}{ Response Category } & \multicolumn{4}{|c|}{ Stimulus Condition } \\
\hline & 1 & 2 & 3 & 4 \\
\hline & \multicolumn{4}{|c|}{ Flight } \\
\hline (A) Opening eyes, pupils dilating, rapid searching, raising ears & 4 & 3 & 2 & 1 \\
\hline (B) Withdrawal & 5 & 4 & 3 & 2 \\
\hline (C) Flight & 6 & 5 & 4 & 3 \\
\hline \multirow{2}{*}{ (D) Wild Flight } & 7 & 6 & 5 & 4 \\
\hline & \multicolumn{4}{|c|}{ Defense } \\
\hline (E) Flattening ears and crouching & 4 & 3 & 2 & 1 \\
\hline (F) Hissing & 5 & 4 & 3 & 2 \\
\hline (G) Growling & 6 & 5 & 4 & 3 \\
\hline (H) Striking with protruded claws & 7 & 6 & 5 & 4 \\
\hline (I) Moving forward, attack & 8 & 7 & 6 & 5 \\
\hline
\end{tabular}

Note-Stimulus Condition 1 = sight of experimenter outside cage; $2=$ opening cage door, waving stick; $3=$ poking with stick; $4=$ trapping in net and releasing. The numbers in each cell indicate the relative weighting of scores.

from this one observer, a factor that should contribute to consistency in scoring over years.

\section{Surgery and Histology}

Standard stereotaxic procedures were followed under sterile conditions, and lesions were placed in the septal nuclei or in the fiber systems by passing current through intracranially placed stainless steel cathodes. Throughout the experiment, various types of electrodes and current strengths were used.

At the end of the experiment, the cats were killed, and the brains were hardened in $10 \%$ formalin and embedded in paraffin. These brains were cut at 20 micrometers, and every 20 th section was mounted and stained with thionine. Extent of the lesions was determined from drawings made from the projected microscopic images. The extent of the lesion was then transferred to predrawn diagrams.

\section{RESULTS}

The results of both behavioral and surgical procedures are presented in Table 2. Lesions were found in a variety of nuclei, and those nuclei sustaining more than 50\% damage in a given subject are marked in Table 2 . The

Table 2

\begin{tabular}{rccccccc}
\hline & \multicolumn{6}{c}{ Behavior } & \multicolumn{5}{c}{ Lesion (More than 50\%) } \\
\cline { 3 - 7 } Cat & Flight & Defense & L & D & M & F & ST \\
\hline 1 & $\downarrow$ & $\downarrow$ & + & + & + & & \\
2 & $\downarrow$ & - & & & & + & \\
3 & $\downarrow$ & $\downarrow$ & & & + & + & \\
4 & - & - & & + & & & \\
5 & - & - & + & & & + & + \\
6 & - & - & & + & & & \\
7 & - & - & & & & & \\
8 & - & - & & & + & & \\
9 & - & - & & + & & & \\
10 & $\uparrow$ & - & & + & + & & \\
11 & - & - & & & & + & \\
12 & - & - & & & & + & \\
13 & $\downarrow$ & - & & + & & & \\
14 & - & - & & & & & $++?$ \\
15 & - & - & & & & & + \\
16 & - & - & & & & & + \\
\hline
\end{tabular}

Note $-L=$ lateral $; D=$ dorsal $; M=$ medial $; F=$ fornix $; S T=$ stria terminalis. behavioral results are marked with arrows for reductions and increments. These represent behavior scores in which all postoperative scores for flight and defense were either below or above the range of preoperative scores for that animal.

It is evident from Table 2 that a reduction in flight was observed in four cats and an increment in one cat. Reductions in defense behavior were observed in two cats. Less striking changes were found in a few other animals. However, the changes in all cases were very moderate, even for those that were outside the previous range of scores. In no case did we see anything like the clear changes observed in cats with amygdala lesions (Ursin, 1965a, 1965b; Ursin \& Divac, 1975).

Inspection of Table 2 makes it clear that none of the lesion types was associated significantly with reduction of flight or defense or both. For animals with lesions in the lateral septal nucleus, one animal showed reduced flight and defense and the other animal was not changed. For the five cats with clear lesions in the dorsal septal nuclei, one showed a reduction, one showed an increment, and three showed no change in flight behavior; for defense behavior, one showed a reduction and four showed no change. There were four animals with clear lesions in the medial septal nuclei; again, two showed a decrement, one showed an increment, and one showed no change in flight behavior, and there was also no consistent picture for defense behavior. The same story is evident for the fiber tracts: For fornix lesions, two animals showed a reduction in flight behavior and two showed no change; three animals showed no change in defense behavior and one animal showed a reduction in defense behavior. Finally, for the three animals with lesions in the stria terminalis, no changes were observed in either flight or defense behavior.

\section{DISCUSSION}

Lesions in different parts of the septal complex of the cat did not produce any consistent change in flight or defense behavior in feral cats. Although there were moderate changes, both increments and decrements, in a few cats, these were not 
consistently related to any particular nuclear structure or k-fiber system. We cannot exclude that even more detailed anatomical breakdown of the nuclei may reveal a consistent picture. If so, however, it is more complex than our present method allows us to analyze.

This lack of obvious effect of septal lesions on a number of defensive behaviors and on flight attempts is interesting in the context of recent findings that septal damage in rats consistently reduces attack by dominant males on colony intruders or subordinates (D. C. Blanchard, R. J. Blanchard, Takahashi \& Takahashi 1977; Lau \& Miczek, 1977) but increases intraspecies defensive behaviors of the attacked or threatened rats (R. J. Blanchard \& D. C. Blanchard, 1980). The present feral cats were extremely defensive in the presence of a human experimenter, but it does not seem likely that the present lack of change represents a "ceiling" effect, since a few animals did show increases in flight or defense. Higher scores have also been obtained in other animals using the same method (Ursin, Note 1).

These results are also difficult to fit within the notion that the posterior perifornical portion of the septum is a core structure in the production of emotionality or that the stria terminalis subserves a modulating influence on such a septal structure. It is the amygdala nuclei that affect these behaviors in the feral cat (Ursin, 1965b), and whatever modulation septal nuclei have on the amygdala is not strong enough to affect flight and defense in the feral cats.

This lack of effect contrasts sharply with the considerable behavioral changes observed in tame cats and rats after septal damage when these animals are tested in conventional learning tasks. These animals show a relatively consistent improvement in two-way active avoidance and a deficit in passive avoidance. Since these are opposite changes in performance of fear-motivated tasks, motivational explanations for such results might either involve the motion of an increase (cf. King, 1958) or a decrease (Lubar, 1964) in fear or emotionality. However, measurements of the corticosterone levels during avoidance learning in rats with septal lesions do not support any such explanation (DeRyck, Kфhler, Ursin, \& Levine, 1976).

An alternative view of the mechanism of septal effects in such tasks is that damage to this area reduces specific defensive behaviors, such as freezing (R. J. Blanchard \& D. C. Blanchard, 1969), and permits a compensatory increase in more active defensive behaviors, such as the "explosive startle," seen especially in rats with damage anterior and ventral to the septum proper (Albert \& Richmond, 1976). Even this limited hypothesis from the rat literature is not supported by the present results: Our subjects continued to crouch or freeze in a very characteristic defense posture (accompanied by hissing and claw baring) after septal damage. Recent data from rats with septal lesions also question the view that a homogeneous change in freezing can explain the active avoidance changes of these animals (Srebro, Ellertsen, \& Ursin, 1976).

In comparing the present results with behavior in avoidance tasks, the issue of septal effects on learning also arises: The flight and defense behaviors observed in this task were behaviors of long standing. It is possible that the septal nuclei are differentially involved in the establishment of flight or defensive behaviors to specific stimulus contingencies. It remains possible that the acquisition of such behaviors might be altered after septal damage, even if the presently established flight and defense behaviors are not.

A recent multifactorial analysis of septal lesions in the rat (Ursin, Dalland, Ellertsen, Herrmann, Johnsen, Livesey, Zaidi, \& $\&$ Whal, Note 2) revealed a very complex factorial picture suggesting that present theories of septal functioning are far too simple. In particular, "inhibition," "freezing," and "activity" occurred in separate and independent factors in the septal-damaged rat. The conclusion from this paper was that our theoretical basis for the analysis of the septal syndrome is too weak, with many of the factors being test specific. It appears likely that ethological analysis will be able to clarify the functioning of this complex structure, but the present results indicate that such analyses must also rely on methods more refined than our present gross identification.

\section{REFERENCE NOTES}

1. Ursin, H. The effect of amygdaloid lesions on flight and defense. Unpublished data, 1965.

2. Ursin, H., Dalland, T., Ellertsen, B., Herrmann, T., Johnsen, T. B., Livesey, P., Zaidi, Z., \& Wahl, H. Multivariate analysis of the septal syndrome. Paper presented at the Ciba Foundation Symposium on Functions of the Septo-Hippocampal System, London, 1978.

\section{REFERENCES}

Albert, D. J., \& Richmond, S. E. Hyperreactivity and aggressiveness following infusion of local anesthetic into the lateral septum. Behavioral Biology, 1976, 18, 211-226.

Andy, O. J., Giurintano, L., Giurintano, S., \& Simpson, P. B. The amygdala in relation to aggressive behavior: Feline experiments in amygdala and perifornical area of posterior septum. In T. Sweet, S. Obrador, \& J. M. Rodriguez (Eds.), Neurosurgical treatment in psychiatry, pain, and epilepsy. Baltimore, Md: University Park Press, 1977.

Blanchard, D. C., BlanchaRd, R. J., Takahashi, L. K., \& TAKAHASHI, T. Septal lesions and aggressive behavior. Behavioral Biology, 1977, 21, 157-161.

Blanchard, R. J., \& Blanchard, D. C. Crouching as an index of fear. Journal of Comparative and Physiological Psychology, 1969, 67, 370-375.

Blanchard, R. J., \& Blanchard, D. C. Animal aggression and the dyscontrol syndrome. In M. Girgis \& L. Kiloh (Eds.), Limbic epilepsy and the dyscontrol syndrome. New York: Elsevier, 1980.

De Molina, A. F., \& Hunsperger, R. W. Organization of the subcortical system governing defense and flight reactions in the cat. Journal of Physiology, 1962, 160, 200-213.

DeRyck, M., Kфhler, C., Ursin, H., \& Levine, S. Plasma corticosterone levels during active avoidance learning in rats with septal lesions. In J. De France (Ed.), The septal nuclei, New York: Plenum, 1976.

KING, F. A. Effects of septal and amygdaloid lesions on emotional behavior and conditioned avoidance responses in the rat. Journal of Nervous and Mental Disorders, 1958, 126, 57-63.

LAU, P., \& Micze K, K. A. Differential effects of septal lesions on attack and defensive-submissive reactions during intraspecies aggression in rats. Physiology \& Behavior, 1977, 18, 479-485.

LUBAR, J. F. Effect of medial cortical lesions on the avoidance behavior of the cat. Journal of Comparative and Physiological Psychology, 1964, 58, 38-46.

Srebro, B., Ellertsen, B., \& Ursin, H. Deficits in avoidance learning following septal lesions in the albino rat. Physiology \& Behavior, 1976, 16, 589-602.

Ursin, H. Flight and defense behavior in cats. Journal of Comparative and Physiological Psychology, 1964, 58, 180-186.

URSiN, H. Effect of amygdaloid lesions on avoidance behavior and visual discrimination in cats. Experimental Neurology, 1965, 11, 298-317. (a)

Ursin, $H$. The effect of amygdaloid lesions on flight and defense behavior in cats. Experimental Neurology, 1965, 11, 61-79. (b)

URSin, H. The cingulate gyrus-A fear zone? Journal of Comparative and Physiological Psychology, 1969, 68, 235-238.

Ursin, H., \& Divac, I. Emotional behavior in feral cats with ablations of prefrontal cortex and subsequent lesions in amygdala. Journal of Comparative and Physiological Psychology, 1975, 88, 36-39.

Zbrozyna, A. W. Strie terminale et reaction de defence. Journal of Physiology (Paris), 1963, 55, 703-704.

(Received for publication February 26, 1981.) 